Winter 2021

\title{
Flight Data Management and Pilot Protection in an ADS-B World
}

James Norman

University of North Dakota, james.e.norman@und.edu

How does access to this work benefit you? Let us know!

Follow this and additional works at: https://commons.und.edu/avi-fac

Part of the Aviation Commons

\section{Recommended Citation}

James Norman. "Flight Data Management and Pilot Protection in an ADS-B World" (2021). Aviation

Faculty Publications. 7.

https://commons.und.edu/avi-fac/7

This Article is brought to you for free and open access by the Department of Aviation at UND Scholarly Commons. It has been accepted for inclusion in Aviation Faculty Publications by an authorized administrator of UND Scholarly Commons. For more information, please contact und.commons@library.und.edu. 


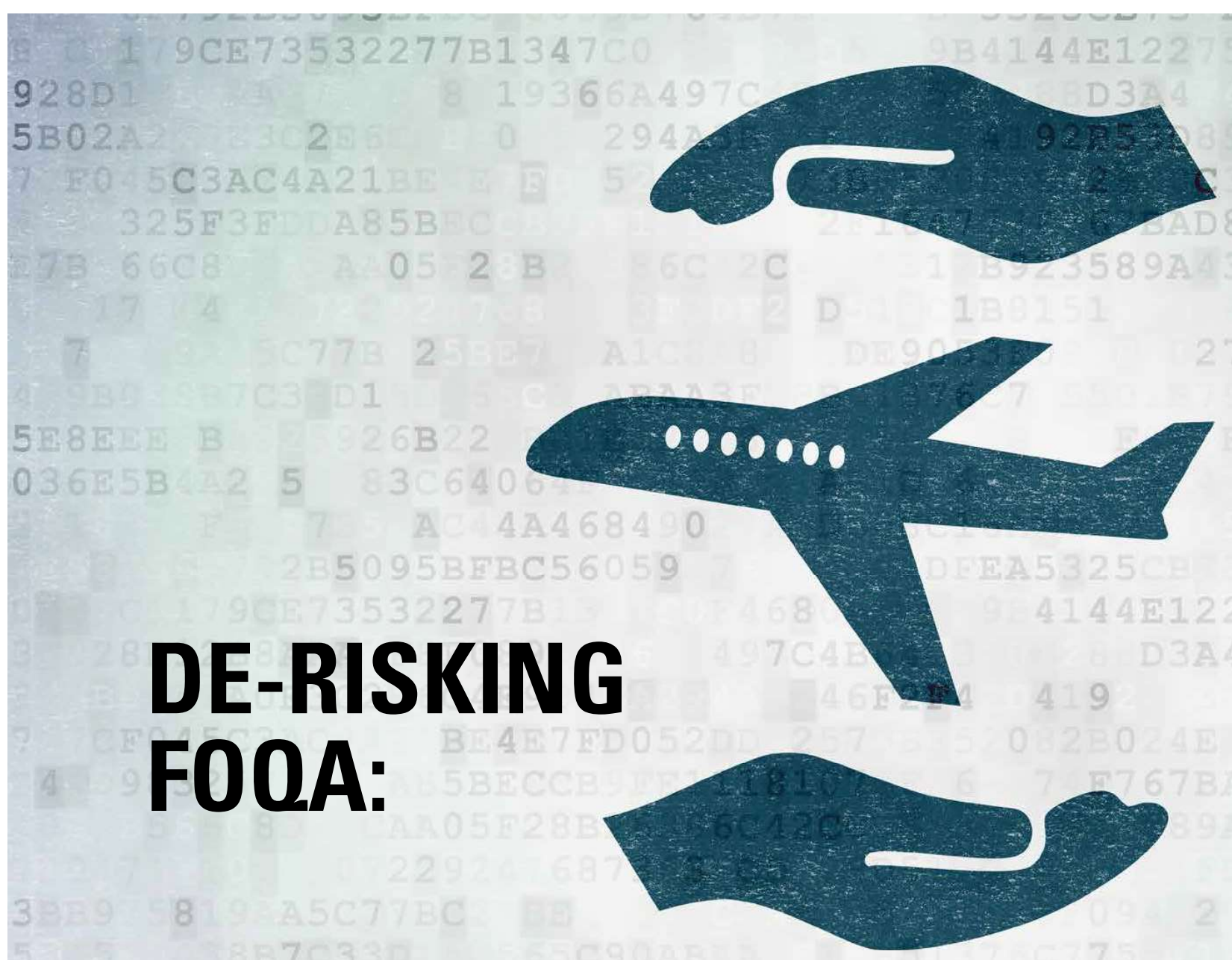

\section{FLIGHT DATA MANAGEMENT AND PILOT PROTECTION IN AN ADS-B WORLD}

Rapid digitalisation of flight data technology may place human operators at potential professional and legal risk without changes to flight operational quality assurance (F0OA) arrangements, according to James Norman.

\section{KEY POINTS}

- Airlines and unions need to reconsider and reimagine what flight operational quality assurance (FOOA) data is, its use and protection.

- Open-source flight data, such as ADS-B, needs to be protected as strongly as traditional FOQA data.

- Airlines and unions should adopt contractual language that expands F00A protections to all recording and transmitting devices, future proofing against emerging and novel technologies.

This issue of HindSight and its focus on digitalisation and human performance comes at an opportune time for a discussion about the consequences of these factors with regard to FOQA
(Flight Operational Quality Assurance) in the US (FDM, Flight Data Monitoring, in the EU). FOQA is considered an essential component of flight safety management, along with its qualitative
"FOQA is considered an essential component of flight safety management"

counterpart, aviation safety action program (ASAP). According to the FAA (Federal Aviation Administration, 2004), FOQA is "a voluntary safety program that is designed to make commercial aviation safer by allowing commercial airlines and pilots to share de-identified aggregate information with the FAA so that the FAA can monitor national trends in aircraft operations and target its resources to address operational risk issues (e.g., flight operations, air traffic control (ATC), airports)." 


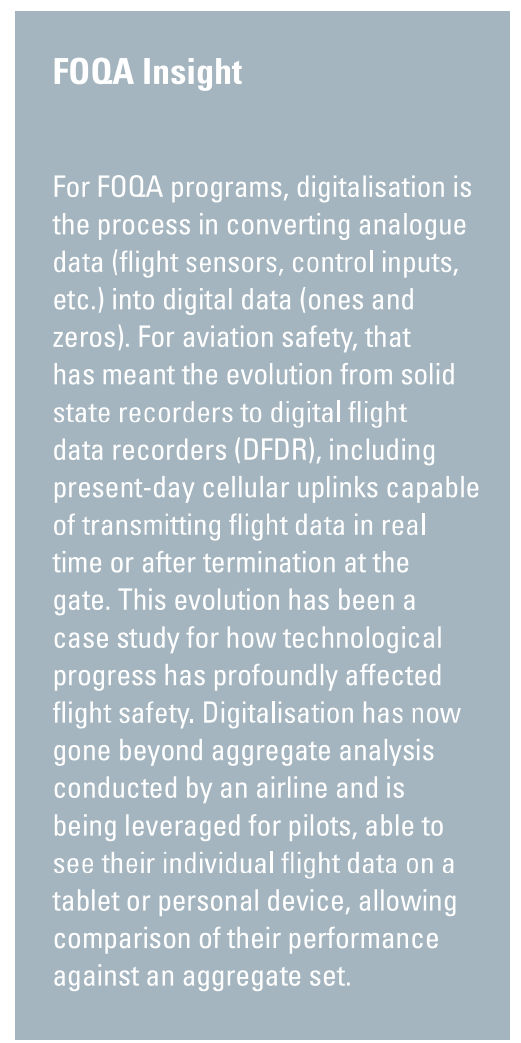

Taken together, FOQA and ASAP bring most of the horsepower that an airline uses to understand line operations by identifying and mitigating hazards. But the two schemes have not developed in tandem. ASAP is currently on its third iteration of FAA guidance (FAA, 2020), but FOQA's guidance remains in its original language as codified nearly two decades ago. The time has come for a reassessment of the tenets of FOQA: its purpose, protections, and uses going forward.

Until very recently, a discussion about flight data in FOQA programs would have been relatively straightforward: data gets downloaded after a flight, ingested onto encrypted servers, scrubbed for exceedances and aggregate trends, and used to further the safety goals of both the airline and the industry. This process was neat and tidy, protected by local letters of agreement between unions and companies as well as by federal law. All participants - from line pilots up to senior management - understood the boundaries of the program. Importantly, programs rarely encountered misuse of flight data, likely because the industry has matured to the point where nearly all FOQA programs are quite similar across airlines. The actors knew their roles. The script was routine...until now.

\section{ADS-B and the open-source era}

Thanks to ADS-B (automatic dependent surveillance broadcast), many aspects of the visibility and use of flight data have shifted into open-source public domain. ADS-B was mandated for most US airspace and its operators in January of 2020. While it is true that the mandate was more burdensome for general aviation than the airlines, the combination of the ubiquity of ADS-B and the open-source nature of its access makes it a game changer. Flight trajectory, ground track and groundspeed are its main components, however actual airspeed and elements like bank angle can also be derived. Did your airline have a rejected take-off or an unstabilised approach? The event can now be captured entirely outside of traditional FOQA methods. And there's no need to stop there; sites like LiveATC. net can allow the general public to tether this pseudo-flight data with the ATC 'tapes' as well.

While faster, better and cheaper access to flight data has been brought about by ADS-B, it comes with a host of issues that need to be urgently addressed if FOQA intends to maintain the buy-in with labour organisations it has earned up until this point. The first issue is the bedrock of any safety program: protection.

\section{The non-disclosure deal}

US federal regulations provide an appealing incentive to airlines: voluntarily share safety information with the FAA, and that information will be protected from disclosure to outside parties. Up to now, this applied to both ASAP and FOQA. Further, a second regulation specifically protects pilots from enforcement action "when such FOQA data or aggregate FOQA data is obtained from a FOQA program" (14 CFR § 13.401). Data obtained outside the FOQA program is fair game for enforcement action, and no proposed rules exist to address this chasm. In a worst-case scenario, it is conceivable that if an airline's FOQA program were to be shut down, much of the data could still be obtained via ADS-B - completely devoid of pilot and company protection, with significant implications for safety culture.

\section{All data is FOOA data}

Given this scenario, it is important to utilise a best-practice phrase in agreements between labour unions and airlines that "all data is FOQA data". Carving out specific uses for FOQA data as solely a flight safety device or maintenance function may have been sufficient in the past, but it is now important that airlines future-proof their contractual labour agreements to protect the company and pilots to the greatest extent. ACARS (aircraft communications addressing and reporting system) data, engine condition monitoring, inflight entertainment systems - anything capable of transmission or recording should be designated as FOQA data. ADS-B's ability to obtain data and operate outside of long-standing federal FOQA protections should sound an alarm bell. It is in the best interest of airlines to make sure non-punitive language at least exists in their systems.

As a disrupter, ADS-B has also forced the industry to call into question other aspects for the purpose of FOQA. The rapidity of data acquisition may influence the human element beyond flight safety per se. For example, what if acceleration forces weren't used just to generate turbulence reports, but also used as a customer satisfaction tool? "Dear Mr. Smith, we regret that you experienced a bumpy ride over Colorado on your last flight; please accept these frequent flyer miles in return." Or with increased attention on sustainability, post-flight customer satisfaction surveys could be enhanced by including emissions savings garnered from single engine taxi or optimised flight planning. There are many scenarios that could see flight data leveraged beyond flight safety, and these uses should be included under the FOQA umbrella to benefit from the protections described previously. 
"Rapid digitalisation, by way

of new flight data technology,

could place human operators

at potential professional

and legal risk if existing

FOOA arrangements are left

unchallenged"

\section{Cameras in the flight deck}

Discussion of different data streams would not be complete without addressing a topic loathed by pilot unions and lauded by the NTSB: cameras in the cockpit. The issue lies at the confluence of digitalisation and human performance undoubtedly. The NTSB reintroduced the recommendation for cockpit image recorders in their most recent 'Most Wanted List'. The NTSB cited recent crashes where such data many have helped to understand the manipulation of flight controls. Cameras may be useful in general aviation where the accident rate has reached a stubborn plateau, and recorders of any type are not required for most operations. However, in airline cockpits, flight data recorders have evolved from forensic devices once rarely used, to essential components of a FOQA program in the present day. Video recognition and machine learning software would need to be designed specifically for an airline cockpit if human performance data were to be digitalised and used in a proactive, meaningful manner. Could FOQA one day create parameters based on kinaesthetic movement? Certainly. But as of now, this technology does not exist.

\section{Whose data is it anyway?}

Finally, we need to ask: whose data is it anyway? Of course, airlines own the data, but it is the pilots who generate the data. A pilot could spend a career generating flight data, revealing interesting or useful insights on how he or she operates the aircraft, yet never be able to access data on their own performance. This is changing with the proliferation of personal monitoring devices and apps. The next generation of pilots may come to expect their personal flight data to be easily accessible to them. Companies are already beginning to cater to this need, and some airlines are implementing it. What is likely to allure pilots to want to access their flight data concerns individual flights or specific events: Was it a hard landing? Was I stabilised? This could gradually see a move away from the aggregate nature that FOQA was originally built upon. Unions and airlines should understand that individual data is most valuable when benchmarked, no matter how interesting or high profile an individual event.

\section{De-risking F00A}

The US aviation safety industry has an opportunity to address and protect against potential stress points for FOQA programs. Rapid digitalisation, by way of new flight data technology, could place human operators at potential professional and legal risk if existing FOQA arrangements are left unchallenged. It is hoped that industry can muster the same collaborative efforts that have been successful before, and FOQA programs can emerge stronger and more valuable than ever. $\mathbf{S}$

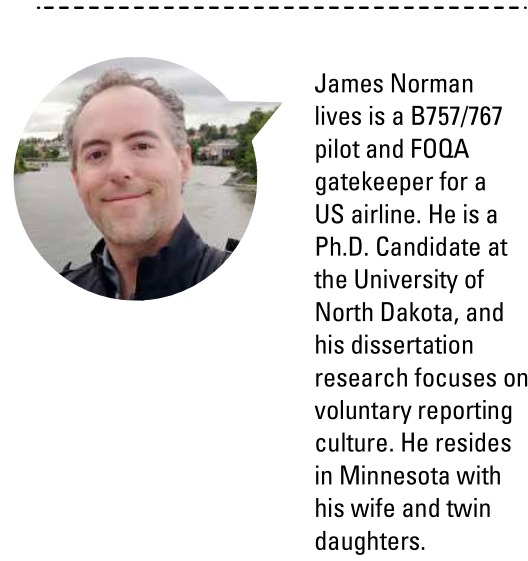

daughters.

\section{Reference}

Federal Aviation Administration (2004, April 12). Advisory Circular 120-82 - Flight Operational Quality Assurance. https://bit.ly/3xuvCDd

Federal Aviation Administration (2020, March 31). Advisory Circular 120-66CAviation Safety Action Program. https://bit.ly/3myqudz 